\title{
Erratum to: Take the wind out your sails: relationship among energy drink abuse, hypertension, and break-up of cerebral aneurysm
}

\author{
Christiano Argano • Daniela Colomba • \\ Tiziana Di Chiara • Ennio La Rocca
}

Published online: 30 March 2011

(C) SIMI 2011

Erratum to: Intern Emerg Med

DOI 10.1007/s11739-011-0523-9

The original version of this article unfortunately contained a mistake in the article title. It should read as follows:
"Take the wind out your sails: relationship among energy drink abuse, hypertension, and break-up of cerebral aneurysm".

The online version of the original article can be found under doi:10.1007s11739-011-0523-9.

C. Argano $(\bowtie) \cdot$ E. La Rocca

Unit of Internal Medicine, San Raffaele-G.Giglio Hospital,

Contrada Pietrapollastra, Cefalù (Palermo), Italy

e-mail: chargano@yahoo.it

D. Colomba · T. Di Chiara

BioMedical Department of Internal Medicine and Specialty

(DiBiMIS), University of Palermo, Palermo, Italy 